\title{
Corporate, Product and Distribution Strategies in the European Life Insurance Industry
}

\author{
Paul J.M. Klumpes ${ }^{\mathrm{a}}$ and Stefan Schuermann ${ }^{\mathrm{b}}$ \\ ${ }^{a}$ Accounting, Law, Finance and Economics, EDHEC, 58 rue du Port, Lille, 59000, France. \\ ${ }^{\mathrm{b}}$ Vontobel Holding AG, Tödistrasse 27, 8022 Zurich, Switzerland.
}

This paper examines corporate, marketing and product distribution strategies in the cost and revenue efficiency across a sample of life insurers that operate in European markets with the highest insurance concentration and density. We predict that these strategies are also affected by segmentation and cross-country differences in regulatory type ("alpine" vs. "atlantic"), which facilitate managerial opportunistic behaviour in choice of distribution strategy. This contrasts with the standard market efficiency hypothesis, which predicts that firms that adopt one of three generic strategies (cost, customer focus and product differentiation) are more efficient than rivals that fail to adopt one of these strategies. Our results support the prediction of the market imperfection hypothesis that firms with nonexclusive distribution systems are less costly and profit-efficient. We also find that firms surviving the recent financial crisis rely on exclusive distribution channels, product differentiation and experience the highest degree of change in cost efficiency over time of increasing deregulation. These findings imply that imperfections in these markets are driven by a combination of tax incentives, regulatory arbitrage and technology transfer of larger firms that exploit their size and dominance to use multiple distribution systems, which are more costly and profit-efficient.

The Geneva Papers (2011) 36, 50-75. doi:10.1057/gpp.2010.38

Keywords: life insurance; efficiency; product distribution

\section{Introduction}

Much of the literature examining efficiency, productivity and performance of the European life industry is dominated by institutional considerations. This reflects a public interest perspective concerning the relation of culture, strategy and performance. By contrast, most U.S. literature on insurer strategy assumes regulation is either endogenous to the choice of overall strategy or is based on a public choice regulatory perspective. Carr et al. ${ }^{1}$ evaluate the strategic and distribution channel practices used by efficient U.S. insurers in a changing regulatory environment. Their study focuses on best practices in overall business strategies, as well as product and marketing strategies by U.S. firms. In this study, we seek to determine whether market imperfections related to management discretion and idiosyncratic factors are more closely associated with superior performance than adopting a "generic" strategy such as cost leadership, customer focus or product differentiation.

\footnotetext{
${ }^{1}$ Carr et al. (1999).
} 
The study concentrates on how the evolving regulatory-strategy framework can affect the linkage between corporate strategy, choice of distribution systems and firm performance. Our study focuses on life insurers operating in the most internationally competitive European countries, such as the Belgium, Austria, the Netherlands, Switzerland, Denmark, Finland and Luxemburg. ${ }^{2}$ These countries have also the highest level of insurance density and are featured by significant concentration of market share by a few dominant and multinational firms. Consequently, evidence on the interaction between corporate strategy, marketing systems and performance in a changing and challenging internationally competitive environment provides important test of the traditional framework used by researchers to examine these linkages in other settings.

We also examine the relationship between efficiency and the adoption of narrow vs. broad product offerings. The objective is to determine whether insurers should choose to specialise and focus on becoming the best in a few products, or to diversify and offer a broad range of products that appeal to a wider variety of customers. The most dramatic changes in the market for insurance have occurred in the area of product distribution systems. The banks, mutual fund companies and investment advisors that have recently entered the insurance market generally can distribute insurance products much more cost-effectively than traditional insurers, particularly in the Atlantic or Maritime countries of Benelux, France and the U.K. This has motivated insurers to look beyond the tied agency/brokerage system and to modify agency compensation systems in an attempt to compete more effectively. There has also been a proliferation in the use of multiple distribution systems by the larger and dominant insurers. We also provide evidence on the success of these innovations in improving firm performance over time. ${ }^{3}$

To measure the association between business strategy, disclosure policy and firm performance, we draw from an extensive survey of actual business practices of insurers. The survey replicated the approach described in Carr et al. ${ }^{1}$ and was administered to a sample of 46 insurers operating in six different European markets. The insurers differ widely in size, product mix, marketing strategies and management practices. Responses from this sample of insurers were then used to measure overall strategies more precisely as well as to identify product and distribution system choices that might influence efficiency. We also analysed the effect of survivorship on performance over time.

Our analysis reveals that European insurers are finding that the right combinations of business strategies are more likely to be efficient than those choosing sub-optimal combinations of strategies (e.g. no clear focus on customers, products or costs). These

\footnotetext{
2 Dreher, (2006).

${ }^{3}$ In evaluating firm performance, we use the concept of economic efficiency and revenue efficiency. Economic efficiency is computed relative to best practice efficient frontiers, consisting of the dominant firms in the industry. Two major types of efficiency are used in our analysis - cost efficiency (the firm's success in minimising costs) and revenue efficiency (the firm's success in maximising revenues). The economic efficiency approach is superior to conventional measurement techniques such as the analysis of expense ratios and net income because it summarises the firm's performance in a single statistic that takes into account differences among firms in product and input mix in a sophisticated multidimensional framework.
} 
results are strongly conditioned by the type of regulatory environment in which these firms operate. Firms that dominate the sector are more likely to face incentives to exploit these advantages to secure a better connection between strategy and performance. These results contrast with those obtained by Carr et al. ${ }^{1}$ for the U.S. industry.

We further corroborate these findings by examining the effect of ongoing consolidation in the industry on the composition of surviving firms with marketing and distribution channels. Firms with product-focused strategies and exclusive distribution systems are more likely to survive over time, and experience significant change in efficiency over time. Overall, the findings suggest that choosing and effectively implementing certain combinations of strategic choices can reduce costs.

The remainder of this paper is organised as follows. In the next section, we provide the institutional background for our study. In the section after that, we discuss various hypotheses that have been advanced in the management, accounting, economics and insurance literatures about the relationship between strategic choices and success in minimising costs and maximising revenues. Data and method issues are discussed in the subsequent section. The results are presented in the penultimate section, and conclusions presented in the last section.

\section{Institutional background}

This section provides the institutional background required to understand the interrelationship between regulatory environment, corporate, product and distribution strategies of European insurers. ${ }^{4}$ It provides a brief overview of the insurance markets, the market structure (e.g. monopolistic or oligopolistic), the number of competitors and the nature of regulations and enforcement in these countries. ${ }^{5}$

Table 1 shows the insurance density (per capita) and penetration (as a percentage of GDP) for the life and non-life markets. Countries initially selected for inclusion in the study are those in which both insurance density (GDP) and concentration (per capita) income for non-life and life insurance are both at least 1 per cent of the world share of the relevant insurance market, are based in countries with significant international competitiveness, and the highest concentration and density. ${ }^{6}$ This procedure resulted in the selection of the non-EU state of Switzerland, as well as

${ }^{4}$ Prior to liberalisation and deregulation in the mid-1990s, the European insurance industry was fragmented and segmented. Large players dominated the industry and heavy tariff regulation limited competition and cross-border activity. Thus, insurers traditionally have been sheltered from price competition that has resulted in low average efficiency and a wide dispersion among firms in the industry. However, the deregulation and harmonisation of accounting, solvency and registration rules across the European Union, together with greater competition from alternative financial services providers, including banks, mutual funds and investment firms, as well as international competition.

5 A more detailed discussion can be found in Klumpes et al. (2007).

${ }^{6}$ While the other main established European markets of Germany, Spain, Italy and the U.K. also have relatively high rates of insurance penetration, differences in capital raising (U.K.), high degrees of segmentation of insurance markets (Germany) and significant barriers to entry and fragmentation of insurance across regions (Spain and Italy) caused us to exclude these countries for analysis. 
Table 1 European market ranking (Density and penetration)

\begin{tabular}{|c|c|c|c|c|c|c|c|c|}
\hline \multirow[t]{4}{*}{ Sample } & \multicolumn{4}{|c|}{ Insurance density } & \multicolumn{4}{|c|}{ Insurance penetration } \\
\hline & \multicolumn{4}{|c|}{ Premiums Per Capita (in U.S. dollars) } & \multicolumn{4}{|c|}{ Premiums as Percentage of GDP } \\
\hline & \multicolumn{2}{|c|}{ Life } & \multicolumn{2}{|c|}{ Non-life } & \multicolumn{2}{|c|}{ Life } & \multicolumn{2}{|c|}{ Non-life } \\
\hline & US\$ & Rank & US\$ & Rank & $\%$ & Rank & $\%$ & Rank \\
\hline Austria & 811.0 & 14 & $1,035.7$ & 8 & 2.59 & 14 & 3.30 & 6 \\
\hline Belgium & $2,004.8$ & 6 & 870.9 & 11 & 6.81 & 3 & 2.96 & 10 \\
\hline Denmark & $2,037.5$ & 5 & $1,078.5$ & 7 & 5.18 & 7 & 2.74 & 11 \\
\hline Finland & $2,126.8$ & 4 & 587.7 & 15 & 6.81 & 3 & 1.88 & 16 \\
\hline Luxemburg & $1,161.1$ & 12 & $1,335.0$ & 5 & 2.09 & 16 & 2.40 & 13 \\
\hline Netherlands & $1,561.7$ & 9 & $1,532.4$ & 2 & 4.93 & 8 & 4.84 & 2 \\
\hline $\begin{array}{l}\text { Switzerland } \\
\text { Excluded: }\end{array}$ & $3,431.8$ & 1 & $2,228.5$ & 1 & 7.72 & 2 & 5.02 & 1 \\
\hline France & $1,767.9$ & 7 & 930.5 & 10 & 5.99 & 6 & 3.15 & 9 \\
\hline Germany & 930.4 & 13 & $1,120.8$ & 6 & 3.17 & 12 & 3.82 & 4 \\
\hline United Kingdom & $2,617.1$ & 2 & $1,441.4$ & 3 & 8.62 & 1 & 4.75 & 3 \\
\hline
\end{tabular}

France, and six relatively small EU states (Austria, Belgium, Denmark, Finland, Luxemburg and the Netherlands). ${ }^{7}$

The overall European insurance market is subject to a mix of European Union legislation and regulations, as well as national regulations. In addition, a significant number of new and proposed financial services directives and laws are expected to facilitate the integration of national insurance markets in the EU and EAA areas. An important consideration is the national supervisory regulatory model(s) pertinent to these markets, as well as the over-arching role of the EU law in standardising provisioning, supervision, solvency and transparency requirements. ${ }^{8}$

Two models of regulatory supervision were identified and briefly discussed by Van den Berghe (p. 215). ${ }^{9}$ Under the normal control system or the "maritime model" (United Kingdom, Ireland, Belgium and the Netherlands), regulations are based on a previous license, coupled with financial guarantees, a solvency margin, sufficient technical reserves, congruent investments and all in a publicity system involving ex post approval.

\footnotetext{
${ }^{7}$ Some countries that qualify for discussion and Norway, an Economic Area Association (EAA) member country that is subject to the third-generation EU directives. Iceland, another EAA member state, was excluded from the analysis, because there were insufficient institutional background data available.

${ }^{8}$ Prior to the recent development of EU regulations, Van den Berghe (1990) characterised the European market as having considerable regional differences in regulatory control. Due to space limitations, we cover this issue only briefly since there are insufficient observations in our sample to provide rigorous empirical evidence on the 'style of regulatory model' on the hypothesised inter-relationship of corporate strategy, choice of distribution system and firm performance.

${ }^{9}$ Van den Berghe (1990, p. 215).
} 
Under the alternative material control system or the "Alpine model" (Austria, Denmark, Finland, Germany and Switzerland), the insurance market is highly regulated and covers not only all the above regulations, but is primarily a prior approval system in which every tariff and every product must be accepted before any activity can begin.

The distinction between "Alpine" and "maritime/Atlantic" is also of importance to understanding the role of distribution systems in this study because whereas tied agent-driven, the latter is broker or independent agent-driven. However, it is unlikely that either model is descriptive of the insurance industry regime operating in any of these countries. First, the normal control system model as described implies a system of effective self-regulation. This form of regulation ensures that firms do not hold levels of reserves that deviate below a social optimum. There is a greater emphasis on disclosure and compliance with broader rules of professional conduct in various technical areas. Second, there have been a number of European Union directives on accounting, solvency and registration of business, as well as integration of economic and social chapters. Finally, firms can "choose" where to register and the dominant multinational firms operating in these jurisdictions have in any case diversified this risk away by setting up multiple branches and distribution systems.

On the other hand, the Alpine model can be criticised for effectively imposing a higher rate of tax on small, newer firms. Consequently, questions of feasibility and cost cast doubt on the overall efficiency of rate regulation. ${ }^{10}$ Moreover, the concept of rate regulation applies to products with capital guarantees; however, the increasing sophistication of consumers in taking on bundled insurance products that involve an aspect of investment risk has facilitated the development of unit-linked products in many European countries. Finally, the traditional demarcation of distribution channels implies the coexistence and separation of independent advisors and direct salesforces. In more recent times, insurance brokerage and intermediation also gradually have been overtaken by Internet-based sales strategies, thus reducing adherence to the strict intermediation practices that are implied by insurance rate regulation.

Currently, the regulatory supervision of insurers in many European states is in a state of transition as regulatory authorities are seeking to merge with banking and investment supervisors. During the past ten years, this allocation of duties has become steadily less appropriate to developments in the financial sector. ${ }^{11}$ Increasingly, financial institutions are merging into larger organisations with both banking and insurance arms. In all seven countries included in the sample, the industry is concentrated in the hands of a relatively small number of large multinational firms, with the top five firms consistently enjoying significantly more than 50 per cent of the entire insurance market. Thus, the cost, revenue and scale efficiencies and technological investments of the larger players significantly enhances the available

\footnotetext{
${ }^{10}$ Munch and Smallwood (1980).

${ }^{11}$ Because of our doubts about the validity of the distinction of Alpine vs. Atlantic models of regulation, and due to constraints with sample size, we restrict our analysis of the effects of regulatory differences in our analysis of survivorship as reported in Table 9.
} 
channels to distribute their products. Since the size and strategy of the larger firms is also likely to be associated with market imperfections, their presence in these relatively small markets is likely to significantly dilute the posited relation between specified firm strategies, firm performance and distribution channel choices.

Each of these major markets has experienced recent growth, especially in the newer investment or unit-linked product areas, but the adverse capital market conditions and the deterioration in capitalisation and investment conditions has led to significant consolidation. The coming implementation of Solvency II, effective 2009, will force insurers to value first their assets, and then their liabilities, at market value. There are also significant exposure issues arising from the implementation of more stringent and consistent risk reporting rules under the proposed IFRS. Consequently, many insurers in the most developed markets have significant exposure to equity. ${ }^{12}$ This is especially a problem in the heavily regulated German and Swiss life insurance markets, where smaller insurers are relatively under-capitalised. ${ }^{13}$

As the new regulations are gradually implemented, more research is needed to examine the implications of convergence in financial reporting and solvency regulations for the incidence of mergers and acquisition activity, cost and profit efficiency, and corporate strategy, particularly as regards risk management and corporate governance effectiveness. We consider these issues in the next section.

\section{Hypotheses development}

In this section, we develop competing market imperfection and product strategy hypotheses concerning the relationship between observed cost and profit efficiency and the strategic mix of product, marketing and asset/liability structure of insurance groups operating in at least one or more of the six insurance markets.

The market imperfection hypothesis predicts that managerial discretion over product distribution strategy is driven primarily by firm size and market power. Unlike unaffiliated firms, the largest European insurance groups have developed strong marketing and distribution strategies, undertaken significant and sophisticated capital raising, operated a complex mix of insurance, intermediation and investment activities, have relatively complex corporate governance structures, and employ relatively sophisticated risk management and financial reporting practices. Although increased competition and merger and acquisitions activity is likely to have improved overall efficiency during the past decade, many European insurance groups are still operating at unsustainable levels of inefficiency.

This situation contrasts with that of U.S. firms. Structurally, Europe is saving for retirement trough (state) pension systems, whereas the U.S. leaves more scope for

${ }^{12}$ However, this equity exposure has significantly reduced in recent years, particularly since the recent recession and the pressure to adopt more conservative risk management policies in accordance with proposed new regulations such as Solvency II.

${ }^{13}$ Extreme caution must be exercised in the interpretation of national industry trends, since they are based on incomplete data provided either by industry association sources or regulatory authorities. Thus the analysis critically relies on the aggregate market analysis provided by members of the associations, and may not be representative of the type of firm against which a firm may wish to benchmark. 
private savings initiatives. Therefore, the U.S. appears to remain more of a growth market for life insurance savings products, also underpinned by a more favourable demographic structure than Europe in general. Whereas U.S. firms have shown strong in managing relatively complex products such as variable annuities, much of the market for insurance in Continental Europe is still dominated by traditional "endowment policies" and the classic and fairly simplistic unit-linked products (i.e. structured similar to a mutual fund, with an additional risk element in order to qualify for tax incentive). Insurance groups that fail to improve are likely to face declining sales and downward pressure on profit margins, leading to their eventual exit from the market either through insolvency, merger or voluntary withdrawal. Even groups successful in one area, such as minimising costs, may be less successful in other areas, such as maximising revenues.

Since the most dominant European insurance groups operate in several markets and tend to offer complex organisational structures, incentive conflicts exist in the allocation of capital, whenever cooperative action is required and utility maximising individuals are faced with alternative activity choices. Consequently potential cost and profit inefficiencies could exist in several dimensions in European insurance groups. The ownership, marketing and asset structure of firms in the insurance industry are internal mechanisms to control incentive conflicts. ${ }^{14}$ The predictions concerning merger and acquisition activity also highlight the need for continuous improvement in business product and marketing strategy.

In evaluating performance, we use the concept of economic efficiency computed relative to best practice efficient frontiers consisting of the dominant insurance groups operating in the major EU markets. Measuring the association between business model strategy and firm performance allows us to develop some inferences concerning the desirability of cross-border EU regulation, by developing a Europe-wide frontier of the major insurance groups with significant exposure to the main European markets. Our analysis takes into account the fact that observed profit or cost efficiencies may be due to exploitation of outsourcing services (e.g. reinsurance or of labour resource), capital raising, information asymmetry and financial strength of insurance groups relative to unaffiliated or specialist firms.

European insurance groups continually make decisions regarding overall strategy, product mix, target markets, distribution systems, risk management practices and information technology. In the remainder of this section, we utilise the analysis of efficiency and competitiveness in the U.S. life insurance industry to develop predictions concerning the relationship of each of these decisions with the expected effects on their efficiency in the light of prevailing theories of firm performance.

Our market imperfection hypothesis contrasts with the efficiency market hypothesis emanating from U.S.-based strategy literature. For example, Porter ${ }^{15}$ argues that firms that clearly follow one of three generic business strategies tend to outperform other competitors with strategies that do not. This argument holds that a firm with a clear focus is one that has carefully identified its strengths and weaknesses in a competitive

\footnotetext{
${ }^{14}$ Mayers and Smith (1981).

${ }^{15}$ Porter (1980, 1985).
} 
framework. The three generic strategies are cost leadership, customer focus and product differentiation. A cost leadership strategy is one in which firms adopt a strategic focus on cost minimisation, price leadership and efficiency. A customerfocused strategy is one in which the firm concentrates on specific geographic or customer groups and is customer-oriented rather than product-oriented. A product differentiation strategy involves a firm offering a relatively extensive and integrated range of financial services products. We predict that firms that adopt a cost leadership strategy will have a higher level of cost efficiency than one that adopts either a customer-focused or product differentiation strategy. However, any of the three strategies could be associated with revenue efficiency. We undertake an industry survey to rank a series of statements that define corporate strategy along the dimensions of cost leadership, customer focus and product differentiation. The classification mechanism is defined in the Appendix and follows the approach used by Carr et al. (p. 125). ${ }^{1}$ These classifications are then used to determine whether differences in efficiency across insurance groups are at least partly attributable to differences in strategic focus.

In addition to choosing product offerings and targeting markets, insurance groups also face strategic decisions about the way to distribute their products and services. Distribution strategy can thus have a significant impact on efficiency. The most common method of distribution is the exclusive agency system. The company builds its own salesforce by recruiting, financing, training and supervising agents to exclusively represent it.

Insurance is also sold through brokers who represent several competing insurers. The system includes insurers using insurance brokers as well as marketing through financial intermediaries. Direct response marketing is also used. The insurer targets potential clients and uses mail, telephone, mass market advertising and the Internet to market products. These practices are sometimes restricted by domestic law. ${ }^{16}$

In recent years, many of the larger European insurers have mitigated these differences by employing multiple distribution systems, including Internet and mass marketing as well as the use of intermediaries. Thus, the markets have segmented between specialist, small insurers, which rely on a single distribution channel, and larger multinational firms that exploit information technology and scale economies to sell their products. Measuring profit and cost efficiencies is important for distinguishing alternative hypotheses that potentially explain the coexistence of alternative marketing distribution channels in the U.K. life insurance product market. According to the market-imperfections hypothesis, independent financial advisors survive while providing the same services as direct salesforces because of the existence of market imperfections. Thus, the largest, most dominant firms are expected to earn supernormal risk-adjusted profits, while relatively cost and/or revenue inefficient firms will earn risk-adjusted profits closer to normal levels. Alternatively, the productquality hypothesis states that the higher costs of independent financial advisors

\footnotetext{
${ }^{16}$ However, in Alpine Investments BV vs. Minister van Financien (Case C-384/93) [1995] ECR I - 1141, the European Court of Justice held that national regulations restricting these practices hinders trade across Member States.
} 
Table 2 Strategic and control variables: Expected effects on efficiency

\begin{tabular}{lc}
\hline Variable $(+(-)$ & Expected effect on efficiency \\
\hline General strategy & $(+)$ \\
Cost Leadership & $(+)$ \\
Product Differentiation & $(+)$ \\
Customer focus & $(+)$ \\
Mixed & $(-)$ \\
Lines of Business & $(+/-)$ \\
Life & $(+/-)$ \\
Combined & $(+/-)$ \\
Other & \\
Distribution systems choice & $(+/-)$ \\
Non-exclusive dealing & $(+/-)$ \\
Exclusive dealing & $(+/-)$ \\
Direct & \\
Control variables & $(+)$ \\
Size & $(-)$ \\
Growth rate &
\end{tabular}

represent expenses associated with producing higher product quality or greater service intensity, and implies that customers prefer to pay more for "higher quality" products. $^{17}$

Table 2 sets out the predicted relationship between fit and performance. Fit is identified as the distribution channel that mitigates opportunism and transaction costs for a given breadth of product range, leading to relatively superior performance in terms of firm efficiency. Grouping insurance groups by product marketing channel, we test for statistically significant differences in the relative efficiency of firms in the different cells after controlling for the fact that the product range is broad or narrow, defined in terms of whether firms specialise in life insurance or are composites.

These arguments contrast with the standard U.S.-based arguments promulgated in Carr et al. ${ }^{1}$ which assert that insurers distributing products through brokers are expected to be more successful if they focus on a narrower range of products and also if they focus on more standardised products than insurers using agents. The predicted relationship between firm size and efficiency also relates to the economic concept of economies of scale. Economies of scale increase when firms are able to operate at lower average costs per unit. Because of the link between firm size and average costs, it is important to control for size effects when measuring the impact of other strategic decisions on efficiency differences. Firm size is measured as the value of firm assets exclusive of separate accounts. Since European firms vary widely in size within our

${ }^{17}$ Klumpes (2004). 
sample, the value of assets is transformed by taking the natural logarithm of assets into account.

We have strong reasons to believe that market imperfections, as captured by size and economies of scale, will dominate the traditional product-based strategies in a more efficient insurance market. By focusing on a small number of tightly defined markets, a European insurance group might increase its ability to become the dominant player in those markets, even if it is not especially large in absolute terms. Small, focused, lean organisations may have an advantage over larger rivals that pursue a broader marketing strategy either in terms of product offerings or geographical scope of operations. On the other hand, if more efficient firms are more likely to achieve market share gains, we may observe larger firms with broader marketing strategies dominating many markets. In any event, if there is a relationship between market share and firm performance, it must be taken into account when analysing other drivers of efficiency. ${ }^{18}$

Finally, firms that are growing more rapidly than their competitors might exhibit lower levels of efficiency because costs associated with market research, product development, marketing and initial sales expenses can adversely impact current earnings. Therefore, a firm that pursues a more rapid growth strategy should expect to have relatively lower levels of efficiency, at least in the short term. To properly identify the drivers of efficiency differences, we need to control for differences among insurers in growth rate. Growth rate is measured by the average annual change in premium income between 1995 and 2007.

\section{Data and methodology}

\section{Methodology}

In this section we follow the Carr et al. (p. 136) ${ }^{1}$ methodology to explore the relationships between business strategies and efficiency by correlating insurer efficiency scores obtained from an analysis of insurer financial data with the business practices identified in the questionnaire survey. The principal types of efficiency analysed are cost efficiency and profit efficiency. ${ }^{19}$ These estimates are taken from a

\footnotetext{
${ }^{18}$ The most common measures of market share are share of premiums, line or business, or national market, or share of assets held by the firms. Because market power measures are not consistent across EU countries, we followed Carr et al. (1999) by using the natural logarithm of the total value of admitted assets as our measure of firm power.

${ }^{19}$ Life insurance firms are increasingly using benchmarking techniques to identify decision-making units that need improvement by comparing their performance with other firms operating in the industry. An important new class of benchmarking methods has been developed called frontier efficiency methodologies. The frontier methodologies measure firm performance relative to "best practice" frontiers derived from all other firms in the industry. Such measures are superior to traditional techniques such as financial ratio analysis because they summarise firm performance in a single statistic that controls for differences among firms using a sophisticated multidimensional framework. Frontiers can be estimated to measure firm success in employing technology (technical efficiency), attaining optimal size (scale efficiency), minimising costs (cost efficiency), maximising revenues (revenue efficiency) and maximising profits (profit efficiency).
} 
60

separate study of the European insurance industry, reported by Fenn et al. ${ }^{20}$ using stochastic frontier analysis. $^{21}$

The approach taken to identify best practices is to correlate the data on business practices obtained from the questionnaires with the efficiency scores obtained from cost and revenue-efficient frontiers. The efficient frontiers used in Fenn et al. (p. 90) ${ }^{21}$ are estimated using insurer financial data on quantities of both output (expected present value of future claims) and input (total capital and reserves, labour and debt capital), as well as input prices (e.g. insurance wage variables, rate of interest). The frontiers are estimated using data envelopment analysis (DEA). The efficient cost frontier represents the lowest costs attained by firms in the life insurance industry in producing a given bundle of outputs (e.g. present value of insured losses); the efficient revenue frontier represents the maximum revenues earned by firms in the industry while consuming a specified amount of inputs. These are best practice frontiers in the sense that they represent the minimum costs and maximum revenues, respectively, actually attained by firms operating in the industry. ${ }^{22}$

Given the estimates of cost and revenue efficiency, following Carr et al. ${ }^{1}$ a twostage analysis is conducted to identify business practices that are related to higher levels of efficiency. In the first stage, the categorical analysis, we calculate average efficiencies for firms using various business strategies and combinations of strategies that were identified as potentially efficiency-enhancing in our survey. For example, we calculate average efficiencies for firms by distribution system (e.g. exclusive vs. nonexclusive agents) and range of product offerings (e.g. broad vs. narrow). Statistical tests are conducted to determine whether specific combinations of business strategies are more efficient than alternative strategy combinations. In the second stage of the analysis, we utilise multiple regression analysis to search for efficient business practices. Multiple regression analysis enables us to identify efficient practices while

\footnotetext{
${ }^{20}$ Fenn et al. (2008).

${ }^{21}$ Carr et al. (1999, p. 136) use cost and revenue efficiency scores that were estimated using a mathematical technique known as data envelopment analysis (DEA). DEA is a mathematical programming methodology that is implemented by solving linear programming problems. DEA efficiency is measured for every firm observation in our sample of firms. However, Fenn et al. (2008) use stochastic frontier analysis, which estimates econometric production, cost, revenue and profit frontiers. The econometric approach differs from DEA in that it involves the use of a specific functional form for the frontiers. Another advantage of this approach is that it simultaneously controls for the impact of heterosketasticity on the estimation of scale economies as well as estimating the effect of firm size and market structure on $\mathrm{X}$-inefficiency. On the other hand, DEA is non-parametric and thus does not require that the analyst specify a functional form. Cummins and $\mathrm{Zi}$ (1998) provide a further comparison of the two methods.

${ }^{22}$ Carr et al. (1999) note that in estimating the DEA cost frontier, a mathematical algorithm is used to find a combination of firms operating in the industry that jointly could produce a given insurer's outputs at a lower cost for a given set of input prices. If no such combination can be found, the given insurer is identified as "self-efficient" and given an efficiency score of 1.0. If a set of firms can be found that jointly dominates the given insurer, the insurer is identified as being less than fully efficient. Its efficiency score is the ratio of the costs that would have been expended by the dominating combination of firms to the costs the insurer actually expended. The score is between 0 and 1 with higher scores indicating higher efficiency. For example, an efficiency score of 0.75 indicates that the given insurer is operating at 75 per cent of full efficiency, or equivalently that it could reduce its costs by 25 per cent, while still producing the same level of output if it operated with the level of efficiency attained by the dominating set of firms.
} 
holding constant other firm characteristics such as size that are likely related to efficiency. This is important because business practices may be related to the firm characteristics that are held constant in the regression analysis. For example, if distribution systems are correlated with firm size, we would not want to conclude that a given distribution system is more efficient than the alternatives when we are actually observing only a size effect.

Efficiency is measured by estimating best practice efficient frontiers based on a relevant sample of firms. The firms on the frontier are considered to be the best practice firms in the industry in the sense that their performance is at least as good as that of other firms with similar characteristics. The efficiencies of other firms in the industry are measured in comparison to the efficient frontier.

The objective in estimating any given firm's efficiency is to define a set of other firm observations from the industry that dominate the firm observation in question. For example, in estimating technical efficiency (see below) we are seeking a set of firm observations that have lower inputs than a specific firm while having similar outputs. The dominating set of "efficient firms" consists of at least one firm observation, and the number of firm observations for each firm averages about ten. If a dominating set exists, then the specific firm observation's efficiency is measured relative to this set. If no dominating set exists, the firm's performance observation is considered self-efficient and given an efficiency score of 1 . All efficiency scores range from 0 to $1 .^{23}$

Efficiency scores are correlated with business practices using a two-stage approach. In the first stage, the categorical analysis, we compute average efficiencies for insurers with different combinations of product strategies, marketing strategies and technical capabilities. Life insurers are categorised based on size, business concentration and distribution strategy to determine whether significant differences in average efficiency exist across groups. These tests provide evidence on hypotheses concerning combinations of business strategies that are likely to be successful.

In the second stage, Carr et al. ${ }^{1}$ examine relationships between business practices, and efficiency is examined using multiple regression analysis. ${ }^{24}$ This econometric procedure measures the effect of each independent variable on efficiency while holding constant (controlling for) the effects of other variables included in the equation. Separate equations are estimated for cost and profit efficiency.

\section{Sample selection and data}

The questionnaire, described in the Appendix, was sent to approximately 150 insurers based in the major continental European Union states that transact insurance business. We did not survey the U.K. industry, due to the size and market penetration

${ }^{23}$ In estimating the DEA cost frontier, a mathematical algorithm is used to find a combination of firms operating in the industry that jointly could produce a given insurer's outputs at a lower cost for a given set of input prices.

${ }^{24}$ Carr et al. (1999, p. 138) provide a basic description of the procedure of multiple regression analysis, which involves estimating a linear equation that relates efficiency to a set of strategy and control variables, in order to infer whether a statistically significant positive or negative association exists between these variables. 
Table 3 Sample selection-European insurance firms in 1995 and surviving to 2007

\begin{tabular}{lccc}
\hline Country & Total sample 1995 & Non-survivors & Survivors 2007 \\
\hline Austria & 4 & 2 & 2 \\
Belgium & 6 & 3 & 3 \\
Denmark & 3 & 1 & 2 \\
Finland & 3 & 2 & 1 \\
France & 2 & 2 & 0 \\
Luxemburg & 6 & 4 & 2 \\
Netherlands & 9 & 4 & 5 \\
Switzerland & 7 & 2 & 5 \\
Total & 40 & 20 & 20 \\
\hline
\end{tabular}

Notes: This table shows the number of life insurance firms originally surveyed in 1999-2003. The firms surveyed subsequently either survived in their current form to 2007 or were restructured and/or taken over by other entities. Survivors are treated as firms that were in continuous existence during the period under their original registration name and had financial statements available for the entire period of 1995-2007 for analysis. Approximately half of the sample firms were either taken over, were merged or no longer provided financial information for analysis purposes during the sample period. Atlantic countries are defined to include the Benelux countries and France (although the two French firms originally surveyed did not survive to 2007). Alpine countries are defined to include Austria, Finland, Germany and Switzerland. Approximately half of the firms included in the analysis were firms that were in the top five insurers that had at least 50 per cent market share. Of the firms remaining in 2007 , approximately 70 per cent were large insurers.

differences with continental European states, and since the U.K. did not adopt currency or interest rate convergence during the study period. A total of 46 responses were received, or one-third of the initial sample. These were spread evenly across the major and minor continental European insurance markets (Austria, Belgium, Denmark, Finland, France, Germany and Netherlands). Of these, approximately 40 per cent were provided by industry dominating players and the remaining 60 per cent by relatively small "niche" players.

Data was also collected over the subsequent five periods of the survey (2003-2007); this enabled us to clarify the impact of survivorship on the performance of firms using particular strategies over time. Of these respondents, only 19 firms survived over the subsequent five-year period (i.e. just under half the firms who initially participated in the questionnaire study). The final sample size and their country breakdown is reported in Table 3. The significant consolidation of firms in the industry highlights the important role played by the dominant multinationals in exploiting their size and informational advantages to leverage their strategy through the use of multiple distribution channels in these markets. ${ }^{25}$ Further tests of the effect of probability of survival on firms' declared strategy are reported in sections "Survivorship of product

\footnotetext{
${ }^{25}$ The sample is roughly evenly divided between Atlantic-regulated countries (the Benelux countries) and "Alpine model"-regulated countries (Austria, Finland, Germany and Switzerland). Three companies from France were also included in the initial analysis, although none of these firms continued in existence to 2007. Therefore, although they are included in the initial analysis reported in Tables 4-7, they are not analysed as part of the effect of regulatory regime on survivorship.
} 
and marketing strategies over time" and "Analysis of determinants of changes in efficiency over time" below.

The table shows that approximately half of the firms that were included were registered in countries that adopted the "Atlantic model" of regulation (namely, the "Benelux" countries), and the remainder were attributed to the "Alpine model" (i.e. Austria, Denmark, Finland, Germany and Switzerland). ${ }^{26}$ Exactly half of the firms originally surveyed in 2002 did not remain in existence, or were taken over, or did not provide financial statements for the subsequent "post crisis" period ending 2007-2008. Approximately half of the firms included in the intial analysis were also large multinationals or were "top 5" players in the sector for the respective country, while the remainder were "boutique" or focused/undiversified or non-affiliated firms. Of interest to this study (although not its primary objective), less than half of the unaffiliated small firms survived for the duration of the study (i.e. 2007-2008).

\section{Empirical results}

\section{Categorical analysis}

Table 4 reports the relationship between distribution strategy, firm size and efficiency. Firms are classified into two groups based on assets. Following Carr et al., ${ }^{1}$ firms were asked to identify the primary distribution system used to sell retail life insurance. On the basis of these responses, firms were classified as either non-exclusive (NEX), exclusive (EX) or direct (D). The average cost and revenue efficiency scores for each group are shown in Table 4.

We conduct significance tests for differences between the efficiency scores by category. Three separate tests were conducted; (1) the Wilcoxon test, which is a nonparametric test for differences in location (central tendency) across categories; (2) a non-parametric test for differences between medians; and (3) a small sample $t$-test for differences between means. Tests involved pair-wise comparisons between exclusive vs. non-exclusive, and not large (small) exclusive vs. small.

$\mathrm{P}$-values are given for cases where the comparisons are statistically significant at conventional levels (10 per cent or better). Low P-values are indicative of statistical significance. Comparisons that are not statistically significant are denoted by NS. Statistical tests involving direct salesforces are not conducted due to the small sample size.

The results do not support the efficient market hypothesis that large insurers have any significant efficiency advantage over smaller competitors. Large insurers are not significantly more efficient than small insurers in terms of cost efficiency and revenue efficiency. These results also contradict those reported by Carr et al. (p. 140) ${ }^{1}$ for U.S. life insurers.

\footnotetext{
${ }^{26}$ Although the Scandinavian countries of Denmark and Finland are nominally included in the "Alpine model", since insurance in those countries is integrated with public services, this is a somewhat strong assumption, but is necessary in order to retain sufficient sample sizes to test the effect of regulatory regime.
} 
Table 4 Efficiency, size and distribution strategy

\begin{tabular}{|c|c|c|c|c|c|c|c|}
\hline \multirow[t]{2}{*}{ Size } & & \multirow[t]{2}{*}{ Non-exclusive } & \multirow[t]{2}{*}{ Exclusive } & \multirow[t]{2}{*}{ Direct } & \multicolumn{3}{|c|}{ Non-exclusive vs. exclusive } \\
\hline & & & & & Total & Wilcoxon & t-statistic \\
\hline \multicolumn{8}{|l|}{ Cost efficiency } \\
\hline \multirow[t]{3}{*}{ Not large } & Mean & 0.5956 & 0.4329 & 0.4329 & 0.5321 & NS & NS \\
\hline & Std Dev & 0.5338 & 0.5326 & 0.5460 & 0.5460 & & \\
\hline & $N$ & 19 & 4 & 22 & 20 & & \\
\hline \multirow[t]{3}{*}{ Large } & Mean & 0.4597 & 0.0211 & 0.3828 & 1.052 & NS & NS \\
\hline & Std Dev & 0.5296 & 0.5288 & 0.5255 & 0.0136 & & \\
\hline & $N$ & 12 & 11 & 2 & 24 & & \\
\hline \multirow[t]{2}{*}{ Total } & Mean & 1.0553 & 1.0539 & 1.0576 & & NS & NS \\
\hline & Std dev & 0.0162 & 0.1130 & 0.1496 & & & \\
\hline \multirow[t]{2}{*}{ Not large vs. large } & Wilcoxon & NS & 0.434 & NS & & & \\
\hline & $t$-statistic & NS & NS & NS & & & \\
\hline \multicolumn{8}{|l|}{ Profit efficiency } \\
\hline \multirow[t]{3}{*}{ Not large } & Mean & 0.3773 & 0.4443 & 0.4120 & 0.8433 & NS & NS \\
\hline & Std Dev & 0.4271 & 0.4251 & 0.4251 & 0.0684 & & \\
\hline & $N$ & 19 & 4 & 22 & 20 & & \\
\hline \multirow[t]{3}{*}{ Large } & Mean & 0.3859 & 0.5034 & 0.4329 & 0.8662 & NS & NS \\
\hline & Std Dev & 0.4457 & 0.4361 & 0.4451 & 0.0589 & & \\
\hline & $N$ & 12 & 11 & 2 & 24 & & \\
\hline \multirow[t]{2}{*}{ Total } & Mean & 0.8591 & 0.8536 & 0.8443 & & NS & NS \\
\hline & Std dev & 0.0666 & 0.8856 & 0.0635 & & & \\
\hline \multirow[t]{2}{*}{ Not large vs. large } & Wilcoxon & NS & 0.4305 & NS & & & \\
\hline & t-statistic & NS & NS & NS & & & \\
\hline
\end{tabular}

\section{Multiple regression analysis}

The comparisons above suggest that there may be a more complex relationship between distribution system choice, market strategies technology and efficiency. Following Carr et al. ${ }^{1}$ we conduct regression analysis that enables us to account for complex relationships between firm characteristics and efficiency by measuring the contribution of specific variables to efficiency while controlling for the influence of other firm characteristics that simultaneously affect efficiency. ${ }^{27}$ The estimated

${ }^{27}$ Carr et al. (149) note that regression analysis uses a statistical procedure to estimate a linear relationship between a dependent variable (in this case, efficiency) and a set of independent or explanatory variables. The coefficient on any given explanatory variable is interpretable as the effect of this variable on the dependent variable (efficiency) after accounting for the effects of all the other explanatory variables included in the equation. The two principal types of efficiency, cost and profit, are used as dependent variables in the analysis. 
Table 5 OLS regression analysis: Cost and revenue efficiency

\begin{tabular}{lcc}
\hline Variable name & $\begin{array}{c}\text { Model 1: Parameter } \\
\text { estimate }\end{array}$ & $\begin{array}{c}\text { Model 2: Parameter } \\
\text { estimate }\end{array}$ \\
\hline Dependent variable (type of efficiency) & Cost \\
\hline Intercept & $0.731^{* * *}$ & $0.775^{* * *}$ \\
Life premiums as a fraction of total premiums & 0.055 & 0.082 \\
Composite $(=1$ ) & 0.005 & 0.018 \\
Dominant distribution type is exclusive & 0.094 & $0.110^{*}$ \\
Dominant distribution type is direct & 0.037 & 0.033 \\
Average annual growth in premia & -0.012 & 0.001 \\
Regulatory type & $0.086^{* * *}$ & $0.091^{*}$ \\
Log of admitted assets excluding separate accounts & 0.007 & 0.003 \\
Dummy variable $=1$ for self-declared cost leadership strategy & 0.081 & 0.004 \\
Dummy variable $=1$ for strategic focus on customers and & 0.017 & 0.056 \\
customer groups & & \\
Dummy variable $=1$ for self-declared product leadership strategy & 0.037 & 46 \\
Average annual growth in operating expenses & 0.038 & 1.204 \\
Observations & 46 & 0.040 \\
$F$ Statistic & 1.174 & 0.042 \\
$R$ squared & &
\end{tabular}

***Statistically significant at 1 per cent level; *statistically significant at 10 per cent level.

Note: Revenue and cost efficiency variables are based on Fenn et al. ${ }^{21}$ Life premia as a percentage of total premia, average annual growth in premia, and in average growth in operating expenses, are based on the average for the period 1995-2002. Regulatory type is a dummy variable indicating 1 for Benelux countries and zero for Alpine countries. All other variables are based on a dummy variable interpretation of responses to questionnaires. For example, firms using an exclusive distribution channel are marked as "1", and zero otherwise.

regression models are shown in Table 3. The results are reported in a cost and revenue regression (Table 5).

We first discuss the impact on efficiency of overall firm strategy. Carr et al. (p. 147) ${ }^{1}$ posit that firms that adopt one of three generic strategies - cost leadership product differentiation or customer focus - are hypothesised to be more efficient than firms that do not adopt a specific strategy but, rather, occupy the middle ground. Further, of the three strategies, a cost leadership strategy is likely to be associated with higher levels of cost efficiency. The counter hypothesis is that the strategies are too generic to have much explanatory power and are likely to be dominated by industry-specific strategies. ${ }^{1}$

Contrary to the results reported by Carr et al. (p. 148), ${ }^{1}$ none of the three generic strategies are significantly related to either cost or profit efficiency. None of the three generic strategies was significant in the profit efficiency regressions. Thus, our results do not provide support for the Porter hypothesis.

The regressions also reveal that exclusive dealing insurers, that is those that have independent financial advisors that exclusively or primarily represent a single insurer, are positively associated with both cost and profit efficiency. This finding is consistent with evidence based on U.K. life insurers by Klumpes, ${ }^{18}$ and implies that distribution systems is not associated with a product quality hypothesis, since exclusive agents are assumed in theory to be more product quality oriented and hence cost inefficient. 
This suggests that non-traditional competitors such as banks, investment advisors and fund management companies have a significantly different cost distribution system to traditional insurers. On the other hand, direct distributing insurers do not appear to have a competitive advantage in maximising profit or costs over insurers using exclusive or non-exclusive agents and also have a cost advantage over insurers using exclusive agents. Other tests with variables representing a niche-marketing strategy and interaction variables for having a narrow product strategy and using nonexclusive agents, as well as other product distribution combinations, did not yield significant results. These results also contrast with those reported by Carr et al. (p. 148) ${ }^{1}$ who find that U.S. life insurers with exclusive distributions are negatively associated with cost efficiency, but direct distribution systems are positively associated with revenue efficiency. This suggests that market imperfections, rather than product quality, are driving the association for European insurers.

Consistent with the results reported by Carr et al. ${ }^{1}$ the regressions also reveal that product mix is significantly related to efficiency, although this study was unable to obtain consistent data on the proportion of individual to group life premiums. However, composite firms are negatively associated with cost efficiency, implying that life insurance specialists are more cost efficient than composite insurers, although this could be due to higher volume group life contracts.

The seven-year premium growth rate is also inversely related to cost efficiency. This lends support to the evidence in Carr et al. (p. 148) ${ }^{1}$ that rapidly growing U.S. insurers have to make initial investments in underwriting, marketing and administrative costs that are not recovered immediately, and so decrease efficiency. However, this variable is not significantly related to revenue efficiency.

The models also corroborate the findings reported by Carr et al. ${ }^{1}$ that larger firms are significantly more cost and profit efficient than smaller firms, where size is measured by the natural logarithm of assets. Thus, size appears to convey an advantage in both cost and profit efficiency, suggesting that economy of scale and/or scope may explain most of the cross-sectional variation in cost and profit efficiency across the sample.

Several variables were also tested (not reported) to assess the influence of countrybased information technology and risk management on efficiency differences across life insurers. No country differences were found to explain the results (i.e. a dummy variable indicating whether or not the firm was based in an Atlantic vs. Central European or Alpine country). The technology variable that emerged as being consistently most highly related to both cost efficiency is the growth in operating expenses. Other technology-related variables tested include the presence of non-audit fees, the compensation levels paid to the Chief Financial Officer (CFO) and the technology expenditures per policy in force. None of these variables was significantly related to either the cost or profit efficiency in the regression analysis. ${ }^{28}$

\footnotetext{
${ }^{28}$ Carr et al. (1999, p. 148) also analyse various proxies for investment in risk management systems and information technology. They do not find that technology-related variables, such as the presence of an expert underwriting system, information technology expenditures per policy, were significantly related to either cost or revenue efficiency. Insufficient data is available from the respondent firms to analyse these expenditures.
} 


\section{Survivorship of product and marketing strategies over time}

We undertook further analysis of the sample to examine how the continuing ongoing consolidation of the European insurance industry affected the makeup of different marketing and distribution channels in our sample in the five years subsequent to the identified strategy. We first identified which firms continued to be active until 2008, when the latest credit crunch began to bite. We found that just under half the sample survived as active players in the five years after the end of the initial study period. Table 6 reports the univariate tests of the surviving and non-surviving firms.

Relative to non-surviving firms, surviving firms were featured by lower revenue efficiency, less customer-strategic focus and more cost-strategic focus. However, none of these changes were statistically significant. Hence at first glance, the basic composition of the surviving firms is relatively comparable to those of the nonsurviving firms.

In order to explore this issue at a multivariate level, which controls for various firm characteristics, Table 7 reports a logistic regression of the probability of being a surviving firm. Results are run separately for both revenue and cost efficiency.

Table 7 shows that the probability of being a survivor is mostly related to firm size and to cost efficiency. None of the other variables appear to be statistically significantly associated with survival probability. Hence it appears that market imperfections affect both the choice of distribution channel, and appears to be the most important strategic impact of ongoing consolidation in the sector.

\section{Analysis of determinants of changes in efficiency over time}

As identified in the section "Hypotheses development", a large number of firms responding to the initial survey did not survive over the subsequent five years of industry consolidation. An important issue arising from the above section is to undertake a comparative analysis to determine what specific aspects of firm strategy or distribution channel are likely to be associated with change in efficiency over time of the surviving firm sample. A Malmquist index can be used to evaluate the productivity change of a decision-making unit between two or more time periods. It is defined as the product of catch up and frontier shift terms. The catch up (or recovery) term relates to the degree to which a decision-making unit improves or worsens its efficiency, while the frontier-shift (or innovation) term reflects the change in the efficient frontiers between the two time periods. ${ }^{29}$

Table 8 reports the univariate relationship between various measures of frontier, catch up and overall Malmquist analysis differences in firm size, income and sales change over time, choice of customer, product or cost strategy by choice of distribution channel choice. The Malmquist efficiency indices are shown separately both for the period 1995-2007, as well as the two discrete sub-periods of 1995-2002 (pre survey) and 2002-2007 (post survey).

\footnotetext{
${ }^{29}$ Cooper et al. (2007, p. 328).
} 
Table 6 Analysis of surviving and non-surviving firms between 2002-2008: Univariate tests

\begin{tabular}{|c|c|c|c|c|}
\hline & $\begin{array}{l}\text { Surviving } \\
(n=20)\end{array}$ & $\begin{array}{l}\text { Non-surviving } \\
\quad(n=20)\end{array}$ & $T$-test & $\begin{array}{c}\text { Mann-Whitney } \\
U Z\end{array}$ \\
\hline Revenue efficiency & $\begin{array}{c}0.851 \\
(0.078)\end{array}$ & $\begin{array}{c}0.799 \\
(0.043)\end{array}$ & -1.046 & -0.601 \\
\hline Cost efficiency & $\begin{array}{c}1.052 \\
(0.022)\end{array}$ & $\begin{array}{l}1.051 \\
(0.008)\end{array}$ & 0.162 & -0.501 \\
\hline Customer strategy & $\begin{array}{l}0.20 \\
(0.410)\end{array}$ & $\begin{array}{l}0.30 \\
(0.470)\end{array}$ & -0.717 & -0.721 \\
\hline Product strategy & $\begin{array}{c}0.20 \\
(0.410)\end{array}$ & $\begin{array}{l}0.35 \\
(0.489)\end{array}$ & -1.050 & -1.049 \\
\hline Cost strategy & $\begin{array}{c}0.65 \\
(0.489)\end{array}$ & $\begin{array}{c}0.50 \\
(0.513)\end{array}$ & 0.946 & -0.947 \\
\hline Direct distribution & $\begin{array}{l}0.20 \\
(0.250)\end{array}$ & $\begin{array}{l}0.26 \\
(0.452)\end{array}$ & -0.457 & -0.462 \\
\hline Exclusive distribution & $\begin{array}{l}0.30 \\
(0.470)\end{array}$ & $\begin{array}{l}0.42 \\
(0.507)\end{array}$ & -0.772 & -0.778 \\
\hline Regulatory type & $\begin{array}{c}0.500 \\
(0.513)\end{array}$ & $\begin{array}{l}0.576 \\
(0.503)\end{array}$ & 0.509 & -0.514 \\
\hline
\end{tabular}

Note: Revenue and cost efficiency variables are based on Fenn et al. ${ }^{21}$ Regulatory type is a dummy variable indicating 1 for Benelux countries and zero for Alpine countries. All other variables are based on a dummy variable interpretation of responses to questionnaires. For example, firms using an exclusive distribution channel are marked as " 1 ", and zero otherwise.

Table 7 Logistic regressions of the probability of being a survivor in year $t$

\begin{tabular}{lcc}
\hline & $R E$ & $C E$ \\
\hline Efficiency $_{t-1}$ & 8.047 & 5.881 \\
& 6.857 & $3.546^{*}$ \\
Ln(assets) & 0.230 & 0.238 \\
& $0.141^{*}$ & $0.140^{*}$ \\
Customer-focused strategy dummy & 0.365 & 0.446 \\
& 0.745 & 0.749 \\
Product-focused strategy dummy & -0.016 & -0.031 \\
& 0.783 & 0.781 \\
Cost-focused strategy dummy & 0.559 & 0.565 \\
& 0.871 & 0.870 \\
Direct distribution strategy dummy & -0.422 & -0.499 \\
& 0.762 & 0.774 \\
Exclusive distribution strategy dummy & -0.570 & -0.596 \\
& 0.885 & 0.894 \\
Regulatory type & -14.766 & 5.881 \\
Intercept & 11.102 & 4.636 \\
No. of observations & -7.983 & -5.816 \\
Log-likelihood & 5.540 & 3.546 \\
\hline
\end{tabular}

*Significant at the 10 per cent level.

Note: Standard errors are presented below the estimated coefficients. Revenue (RE) and cost efficiency (CE) variables are based on Fenn et al. ${ }^{21}$ for the surviving firms. Ln(assets) is the natural log of total assets for 2003. Regulatory type is a dummy variable indicating 1 for Benelux countries and zero for Alpine countries. All other variables are based on a dummy variable interpretation of responses to questionnaires. For example, firms using an exclusive distribution channel are marked as "1", and zero otherwise. 
Table 8 Malmquist efficiency changes - Univariate tests

\begin{tabular}{|c|c|c|c|c|}
\hline & $\begin{array}{l}\text { Direct distribution } \\
\text { strategy }(n=5)\end{array}$ & $\begin{array}{l}\text { Non-direct distribution } \\
\text { strategy }(n=15)\end{array}$ & T-test & $\begin{array}{c}\text { Mann-Whitney } \\
U Z\end{array}$ \\
\hline \multicolumn{5}{|c|}{ Panel A: Direct distribution strategy } \\
\hline$\Delta$ Size & $\begin{array}{c}6.360 \\
(7.747)\end{array}$ & $\begin{array}{c}5.757 \\
(11.683)\end{array}$ & -0.107 & -0.218 \\
\hline$\Delta$ Income & $\begin{array}{c}4.544 \\
(6.153)\end{array}$ & $\begin{array}{c}3.586 \\
(7.820)\end{array}$ & -0.248 & -0.393 \\
\hline$\Delta$ Sales & $\begin{array}{c}2615.05 \\
(7005.88)\end{array}$ & $\begin{array}{l}-43.297 \\
(432.400)\end{array}$ & -1.492 & -0.185 \\
\hline Customer strategy & $\begin{array}{c}0.40 \\
(0.55)\end{array}$ & $\begin{array}{c}0.27 \\
(0.45)\end{array}$ & -0.539 & -0.549 \\
\hline Product strategy & $\begin{array}{c}0.40 \\
(0.55)\end{array}$ & $\begin{array}{c}0.33 \\
(0.49)\end{array}$ & -0.257 & -0.264 \\
\hline Cost strategy & $\begin{array}{c}0.40 \\
(0.55)\end{array}$ & $\begin{array}{c}0.53 \\
(0.52)\end{array}$ & 0.493 & -0.503 \\
\hline Catch & $\begin{array}{c}1.829 \\
(2.242)\end{array}$ & $\begin{array}{c}2.235 \\
(3.601)\end{array}$ & 0.235 & -0.567 \\
\hline Frontier & $\begin{array}{c}0.918 \\
(0.609)\end{array}$ & $\begin{array}{c}0.694 \\
(0.184)\end{array}$ & -1.314 & -0.480 \\
\hline Malmquist & $\begin{array}{c}1.234 \\
(1.494)\end{array}$ & $\begin{array}{c}1.333 \\
(1.561)\end{array}$ & 0.124 & -0.742 \\
\hline Catch95-02 & $\begin{array}{c}1.081 \\
(0.867)\end{array}$ & $\begin{array}{c}1.43 \\
(1.55)\end{array}$ & 0.468 & -0.393 \\
\hline Frontier95-02 & $\begin{array}{c}0.906 \\
(0.872)\end{array}$ & $\begin{array}{c}0.872 \\
(0.209)\end{array}$ & -0.309 & -0.044 \\
\hline Malm95-02 & $\begin{array}{c}0.918 \\
(0.631)\end{array}$ & $\begin{array}{c}1.109 \\
(1.100)\end{array}$ & 0.364 & -0.393 \\
\hline Catch02-07 & $\begin{array}{c}1.639 \\
(1.261)\end{array}$ & $\begin{array}{c}5.005 \\
(9.593)\end{array}$ & 0.769 & -0.480 \\
\hline Frontier02-07 & $\begin{array}{c}0.925 \\
(0.350)\end{array}$ & $\begin{array}{c}0.826 \\
(0.154)\end{array}$ & -0.899 & -0.131 \\
\hline Malm02-07 & $\begin{array}{c}1.289 \\
(0.890)\end{array}$ & $\begin{array}{c}3.667 \\
(7.016)\end{array}$ & 0.743 & -0.480 \\
\hline Regulatory type & $\begin{array}{c}0.600 \\
(0.516)\end{array}$ & $\begin{array}{c}0.470 \\
(0.548)\end{array}$ & -0.493 & -0.503 \\
\hline & $\begin{array}{l}\text { Exclusive distribution } \\
\text { strategy }(n=9)\end{array}$ & $\begin{array}{l}\text { Non-exclusive distribution } \\
\text { strategy }(n=11)\end{array}$ & $T$-test & $\begin{array}{c}\text { Mann-Whitney } \\
U Z\end{array}$ \\
\hline \multicolumn{5}{|c|}{ Panel B: Exclusive distribution strategy } \\
\hline$\Delta$ Size & $\begin{array}{c}6.134 \\
(14.673)\end{array}$ & $\begin{array}{c}5.723 \\
(6.549)\end{array}$ & -0.084 & -0.646 \\
\hline$\Delta$ Income & $\begin{array}{c}3.193 \\
(9.863)\end{array}$ & $\begin{array}{c}4.344 \\
(4.755)\end{array}$ & 0.343 & $-1.862^{*}$ \\
\hline$\Delta$ Sales & $\begin{array}{c}1872.41 \\
(5323.58)\end{array}$ & $\begin{array}{c}-228.20 \\
(772.96)\end{array}$ & -1.304 & -0.248 \\
\hline Customer strategy & $\begin{array}{c}0.22 \\
(0.441)\end{array}$ & $\begin{array}{l}0.36 \\
(0.505)\end{array}$ & 0.659 & -0.669 \\
\hline Product strategy & $\begin{array}{l}0.33 \\
(0.500)\end{array}$ & $\begin{array}{l}0.36 \\
(0.505)\end{array}$ & 0.134 & -0.138 \\
\hline
\end{tabular}


Table 8 (continued)

\begin{tabular}{|c|c|c|c|c|}
\hline & $\begin{array}{l}\text { Exclusive distribution } \\
\text { strategy }(n=9)\end{array}$ & $\begin{array}{c}\text { Non-exclusive distribution } \\
\text { strategy }(n=11)\end{array}$ & $T$-test & $\begin{array}{c}\text { Mann-Whitney } \\
U Z\end{array}$ \\
\hline Cost strategy & $\begin{array}{l}0.67 \\
(0.500)\end{array}$ & $\begin{array}{l}0.36 \\
(0.505)\end{array}$ & -1.342 & -1.314 \\
\hline Catch & $\begin{array}{c}2.460 \\
(4.735)\end{array}$ & $\begin{array}{c}1.865 \\
(1.454)\end{array}$ & -0.397 & $-1.785^{*}$ \\
\hline Frontier & $\begin{array}{c}0.635 \\
(0.166)\end{array}$ & $\begin{array}{c}0.845 \\
(0.414)\end{array}$ & $1.537^{*}$ & $-1.567^{*}$ \\
\hline Malmquist & $\begin{array}{c}1.260 \\
(2.046)\end{array}$ & $\begin{array}{c}1.347 \\
(0.976)\end{array}$ & 0.126 & $-1.785^{*}$ \\
\hline Catch95-02 & $\begin{array}{c}1.568 \\
(2.045)\end{array}$ & $\begin{array}{c}1.154 \\
(0.540)\end{array}$ & -0.657 & -0.950 \\
\hline Frontier95-02 & $\begin{array}{c}0.838 \\
(0.229)\end{array}$ & $\begin{array}{c}0.915 \\
(0.181)\end{array}$ & 0.841 & -0.567 \\
\hline Malm95-02 & $\begin{array}{c}1.120 \\
(1.467)\end{array}$ & $\begin{array}{c}1.012 \\
(0.376)\end{array}$ & -0.236 & -0.722 \\
\hline Catch02-07 & $\begin{array}{c}7.257 \\
(12.107)\end{array}$ & $\begin{array}{c}1.633 \\
(0.913)\end{array}$ & $-1.60 *$ & -0.798 \\
\hline Frontier02-07 & $\begin{array}{c}0.838 \\
(0.177)\end{array}$ & $\begin{array}{c}0.862 \\
(0.246)\end{array}$ & 0.245 & -0.266 \\
\hline Malm02-07 & $\begin{array}{c}5.237 \\
(8.891)\end{array}$ & $\begin{array}{c}1.305 \\
(0.682)\end{array}$ & $1.59 *$ & -0.722 \\
\hline Regulatory type & $\begin{array}{c}0.56 \\
(0.522)\end{array}$ & $\begin{array}{l}0.45 \\
(0.527)\end{array}$ & -0.429 & -0.438 \\
\hline
\end{tabular}

*Significant at the 10 per cent level.

Note: Change in size, firm income and premium sales are based on the average for the period 2002-2007 and apply to the surviving firms only. Catch, frontier and Malmquist frontier variables are based on changes in these variables over time (i.e. either 1995-2002 or 2002-2007). Regulatory type is a dummy variable capturing whether the firm is registered in an Atlantic country (Benelux) or Alpine country (others). Change in assets is change in log of net assets from 1995-2007. All other variables are based on a dummy variable interpretation of responses to questionnaires. For example, firms using an exclusive distribution channel are marked as " 1 ", and zero otherwise.

For the decision whether to use a direct distribution channel (Panel A), there are no significant changes in any variables over the period. However, for the decision whether or not to use an exclusive distribution strategy (Panel B), there is a significant relationship between efficiency measures. In particular, firms using an exclusive distribution channel have lower frontier efficiency over the entire period of 1995-2007 and exhibit more catch up during the sub-period 2002-2007. However, none of the other characteristics or changes in efficiency score over time appear to be sensitive to distribution channel choice.

Table 9 repeats the analysis using a multivariate OLS regression. Separate regressions are run for each of the three types of Malmquist index, and for each separate sub-time period.

The results in Table 9 show that the choice of a product leadership strategy exhibited catch up during the earlier period of 1995-2002. Those employing a customer leadership strategy and used an exclusive distribution channel experienced most frontier efficiency change in the subsequent sub-period 2002-2007. This suggests that 


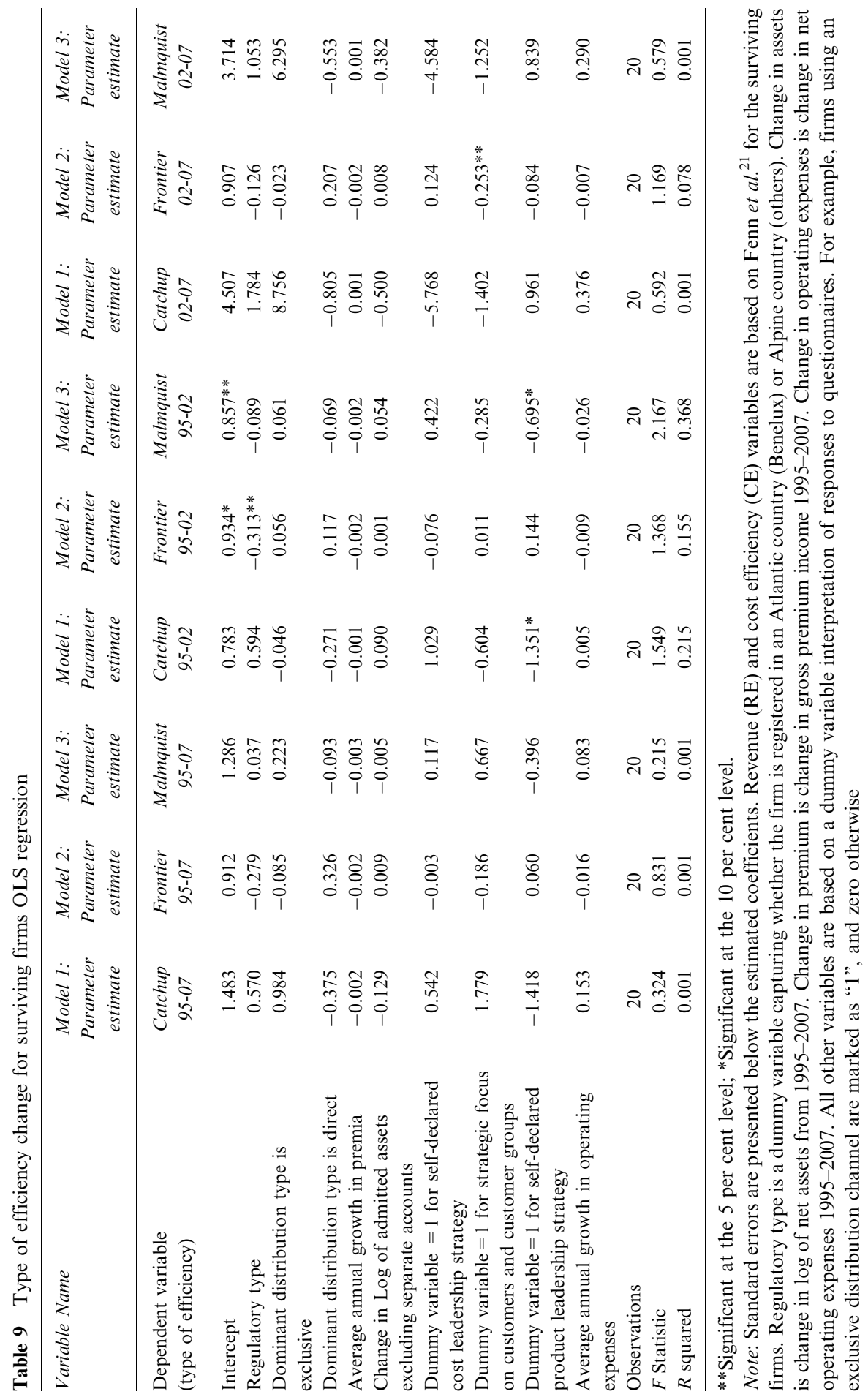


firms with product strategies recovered during the earlier period, but that firms with exclusive distribution channels and customer focus experienced most innovationrelated change in the subsequent sub-period. Regulatory type (whether the firm is registered in a Benelux or Alpine country) appears to explain frontier shift in the early period of 1995-2002, but not subsequently. These results confirm the sensitivity of distribution and marketing strategy to changes in both economic and regulatory environments over time.

\section{Conclusion}

Prior U.S.-based evidence suggests that firm strategy, distribution system choice and performance are inter-related. However, European insurance firms operate in more segmented and fragmented markets, where such choices are also affected by competition from foreign competitors, differences in regulatory environment and a high degree of industry concentration. This study contributes new empirical evidence on this issue by analysing the cross-sectional relationship between size, strategy, cost and revenue efficiency, and distribution system choice for a sample of European life insurance firms spread across six European countries that are featured by international competitiveness, high insurance density and are dominated by multinationals that employ multiple distribution channels. The analysis is important because it establishes whether there are any significant differences in life insurer efficiency attributable to either "market imperfections" or standard firm choices about strategy, product distribution, product mix, and target marketing policy. Such linkages are important in establishing whether economic transaction cost theory or discretionary behaviour by managers associated with regulatory "culture" explains apparent best practices in the European insurance industry.

The evidence suggests that, contrary to equivalent evidence provided by Carr et al. ${ }^{1}$ for the U.S. life insurance industry, there is no support for the transactions cost hypothesis that non-exclusive insurers provide higher revenue efficiency. Nor does our evidence lend support to the Porter ${ }^{16}$ hypothesis that firms which adopt one of three generic strategies (cost, customer focus and product differentiation) are more efficient than rivals that fail to adopt one of these three strategies.

Instead, we find that firms adopting a cost-focused perspective tend to develop greater cost efficiency than those adopting a more general customer or product differential focus. However, these results are not reflected in explaining profit efficiency. This confirms our managerial opportunism prediction that observed variations in efficiency across firms operating in the most dense and concentrated European insurance markets are more likely to be explained by market imperfections than by variations in product quality. European insurance markets have traditionally been much smaller and differentiated in terms of tax incentives as well as distribution models from one country to another. Cost of different local distribution channels differ due to different local salary pay models. In some (especially Continental European) markets, tied agents make up for the bulk of distribution, in other (Atlantic-oriented) markets such as Belgium and the Netherlands, independent financial advisors are more important, but is almost non-existent in Alpine markets. 
Further analysis suggests that the significant consolidation experienced by the sample of European insurers in the subsequent period to 2008 was linked to cost efficiency and to size. Analysis of the changes in efficiency over time further identified that such firms experienced most change in the earlier sub-period 1995-2002, while firms with customer-focused strategies and those employing exclusive distribution channels experienced most innovation-related efficiency change in the subsequent sub-period 2002-2008 leading up to the financial crisis.

Our analysis can be extended in a number of directions, especially in terms of the value generation due to a clear focus on cost, customer or product. For both issues we would add that European wide cross-border IT platforms are not common yet, but first steps in this direction have been taken. This is in our view the beginning of a fundamental change of the insurance model as applied in Europe, with value creation questions on each element of the value chain (production, distribution, administration, asset management) to lead to a more efficient future approach to (life) insurance.

Moreover, our findings support the view that market imperfections, and particularly market power and size, can convey significant advantages in both cost and revenue efficiency. Thus, our overall conclusion is that European insurers cannot significantly improve their operating performance merely by making appropriate strategic choices, but through increasing their efficiency by enhancing their economy of scale or scope. These results are consistent with those of Carr et al. ${ }^{1}$ except that we also control for the effect of increasing regulatory and monitoring costs by explicitly measuring the impact of the growth in operating expenses. Interestingly, we also find anecdotal evidence that firms surviving post the financial crisis had stronger corporate governance structures and were affiliated with financial institutions that did not undergo extensive corporate restructuring.

Subject to these important caveats, our research can be extended to a number of dimensions. Further work is required to extend the sample to include a broader mix of insurers that are more representative of the segmented nature of European markets. The regulatory regime models (Atlantic vs. Alpine) appear to be a crude and possibly outdated way of analysing national differences in registration procedure and regulation across European states. Finally, our analysis did not include detailed analysis of the ongoing risk management, accounting and corporate governance issues that influence firms' propensity to link cost and profit efficiency with product and corporate strategy. Further work is needed to examine the impact of ongoing regulatory change on corporate governance, and technological innovation in both service delivery and information systems.

\section{References}

Carr, R.M., Cummins, J.D. and Regan, L. (1999) 'Efficiency and competitiveness in the U.S. life insurance industry: Corporate product, and distribution strategies', in J. David Cummins and Anthony M. Santomero (eds.) Changes in the Life Insurance Industry: Efficiency, Technology, and Risk Management, Norwell, MA: Kluwer Academic Publishers, pp. 117-157.

Cooper, W.W., Seiford, L.M. and Tone, K. (2007) Data Envelopment Analysis, $2^{\text {nd }}$ Edition, New York: Springer.

Cummins, J.D. and Zi, H. (1998) 'Comparison of frontier efficiency methods: An application to the U.S. life insurance industry', Journal of Productivity Analysis 10: 131-152. 
Dreher, A. (2006) 'Does globalization affect growth? Evidence from a new index of globalization', Applied Economics 38(10): 1091-1110.

Fenn, P., Vencappa, D., Klumpes, P.J.M., O'Brien, C. and Diacon, S. (2008) 'Market structure and the efficiency of European insurance companies: A stochastic frontier approach', Journal of Banking and Finance 32(1): 86-100.

Klumpes, P.J.M. (2004) 'Performance benchmarking in financial services: Evidence from the UK life insurance industry', Journal of Business 77(2): 257-274.

Klumpes, P.J.M., Fenn, P., O’Brien, C., Diacon, S. and Yildrim, C. (2007) 'European insurance market: Recent trends and future regulatory developments', in D. Cummins and B. Venard (eds.) Handbook of International Insurance: Between Global Dynamics and Local Contingencies, New York: Springer.

Mayers, D. and Smith, Jr. C.W. (1981) 'Contractual provisions, organizational structure and control in insurance markets', Journal of Business 54: 407-434.

Munch, P. and Smallwood, D.E. (1980) 'Solvency regulation in the property-liability insurance industry: Empirical evidence', Bell Journal of Economics 11(1): 261-279.

Porter, M.E. (1980) Competitive Strategy, New York: The Free Press.

Porter, M.E (1985) Competitive Advantage: Creating and Sustaining Superior Performance, New York: The Free Press.

Van Den Berghe, L. (1990) ‘(De)regulation of insurance markets’. in H. Loubergé (ed.) Risk, Information and Insurance, Boston: Kluwer.

\section{About the Authors}

Paul Klumpes is Professor of Accounting at EDHEC Business School, Roubaix, France. Previously, he was Professor of Accounting at Imperial College London and Professor of Risk Accounting at Nottingham University Business School. He is an Australian CPA and Honorary Fellow of the Institute of Actuaries. His research interests cover the inter-relationship of public policy and voluntary reporting, regulation, financial management and control of financial services, particularly related to pensions and life insurance.

Stefan Schuermann joined Bank Vontobel as Head of Financials of the Swiss research team in 2008. In 2007, he was active at the leading regional bank EFG-Hermes in Dubai as Head of Real Estate Stocks in the MENA region. From 2005 to 2007, he was a senior sell-side insurance analyst at Credit Agricole Cheuvreux based in Zürich. Before this, since 1999, he was sell-side insurance analyst at Pictet/Helvea in Geneva. Stefan started his professional career in 1994 at Swiss Life, finally being in charge of corporate planning and controlling. He holds a Master degree in Business Administration from Lausanne H.E.C. University.

\section{Appendix}

\section{Definition of porter general strategy variables}

Customer-focused: An indicator variable that is assigned a value of 1 if a firm answers the questions below in such a way as to indicate that it pursues a customer-focused strategy. Otherwise, the insurer is assigned a value of 0 for this variable.

We try to concentrate on geographic and customer groups we already know. We spend a large amount of resources on marketing. 
We spend a lot of resources on monitoring consumer behaviour.

We target the financial planning and security needs of our customers.

We focus on clients who have accumulated wealth, which requires investing, rather than clients who have accumulated little wealth.

We are customer-focused rather than product focused.

Product differentiation: An indicator variable that is assigned a value of 1 if a firm answers the questions below in such a way as to indicate that it pursues a productfocused strategy. Otherwise, the insurer is assigned a value of 0 for this variable.

We try to be "first in" with new or additional distribution channels and marketing concepts.

We try to be "first in" with innovative products.

We seek to be focused on providing an extensive and integrated range of financial services products.

We focus on providing protection rather than savings products.

We seek to maintain and enhance the value of our sales and service system toin and retain clients.

We recognise our agents as an important customer group and invest in training and technology to meet their needs.

Cost leadership: An indicator variable that is assigned a value of 1 if a firm answers the questions below in such a way as to indicate that it pursues a cost leadership strategy. Otherwise, the insurer is assigned a value of 9 for this variable.

We seek to be low cost leaders.

Distribution strategy: An indicator variable that is assigned a value of 1 if a firm answers the question below in such a way as to indicate that it uses a non-exclusive agency, exclusive agency or direct distribution channel.

(1) We use a non-exclusive agency in selling our products.

(2) We only use an exclusive agency in selling our products.

(3) We only use direct salesforce or direct marketing in selling our products.

(4) We only use the Internet to sell our products.

We use a combination of (1)-(4) (please specify) in selling our products. 